\title{
Sentential Negation and Verb Movement in Bantu Languages*
}

\author{
DEO NGONYANI \\ Michigan State University
}

\section{Introduction}

This paper explores a well-known asymmetry between negation marking main clauses and subordinate clauses in Bantu languages (Güldemann 1999:551, Meeussen 1967:114). It is noted that pre-initial negation marking is usually restricted to main clauses, while post-initial marking is rarely restricted. Various studies have explored the diachronic origins of the various strategies. This paper focuses on how the strategies are constrained by clause structure. It is argued that negation projects a NegP as an element of Infl. Asymmetrical negation marking is due to two NegPs, one selecting TP, and the other selected by TP.

The paper is organized into five sections. Section 1 presents examples of strategies of marking negation in main clauses, while Section 2 contains examples of negation in relative clauses. Section 3 discusses verb movement to $\mathrm{C}^{\circ}$ and Section 4 proposes an analysis of NegPs. Section 5 concludes the discussion.

\section{Strategies of Marking Negation in Main Clauses}

Bantu languages exhibit a wide range of negation marking strategies in matrix clauses. Most languages mark negation by means of an affix on the verb. Affixal negation markers are located in one or two slots on the Bantu verbal template.

(1) Elements of the Bantu Verb (adopted from Meeussen 1967:108)

\begin{tabular}{|l|l|l|l|l|l|l|l|c|}
\hline & Pre-initial & Initial & $\begin{array}{l}\text { Post- } \\
\text { initial }\end{array}$ & $\begin{array}{l}\text { Tense \& } \\
\text { Aspect }\end{array}$ & Infix & Stem & Final & $\begin{array}{c}\text { Post- } \\
\text { final }\end{array}$ \\
\hline Function & REL/NEG & SM & NEG & TNS/ASP & OM & Verb & ASP & NEG \\
\hline Negation & + & & + & & & & & + \\
\hline
\end{tabular}

The three slots for negation marking together with independent negative words derive six strategies of marking negation in main clauses as illustrated below.

\footnotetext{
- This paper is based on work supported in part by the Michigan State University Intramural Research Grant Program.
} 
(i) Preverbal particle as in Hung'an H.42 (Takizala 1972:127)

(2)

$$
\begin{aligned}
& \text { lo i-meen kiti }{ }^{2} \\
& \text { NEG I-saw 7-chair } \\
& \text { 'I didn't see the chair.' }
\end{aligned}
$$

(ii) Pre-initial Affix as in Luba L.31 (Yukawa 1992:309, 317)

(3)
a. tw-áka-mu-p-a
we-PT-1OM-give-FV
'we gave him/her'
b. á -tw-aká-mú-p-a
NEG-we-PT-1OM-give-FV
'we did not give him/her'

(iii) Post-initial Prefix as in Nyakyusa (Ngonyani personal notes)

(4)
a. tw-a-piy-ile
We-PT-cook-PF
'We cooked.'
b. tu-ka-a-piy-ile
we-NEG-PT-cook-PF
'We did not cook.'

(iv) Post-final Suffix as in Nkoya L.62 (Yukawa 1987:138)

(5)
a. na-mon-ene
I-see-PT
'I saw.'
b. ná-mon-eně-ha
I-see-PT-NEG
'I did not see.'

\footnotetext{
${ }^{1}$ A letter and a number after the name of a language refer to the reference number assigned in Guthrie's 1968-71 classification of Bantu languages.

${ }^{2}$ Abbreviations:

$\begin{array}{llllll}\text { CON } & \text { Conditional Marker } & \text { DEM } & \text { Demonstrative } & \text { FV } & \text { Final Vowel } \\ \text { FT } & \text { Future Tense } & \text { INF } & \text { Infinitive Marker } & \text { NEG } & \text { Negation } \\ \text { OM } & \text { Object Marker } & \text { PF } & \text { Perfective Marker } & \text { PT } & \text { Past Tense } \\ \text { REL } & \text { Relative Marker } & \text { SM } & \text { Subject Marker } & \text { SUBJ } & \text { Subjunctive Marker }\end{array}$
}

The numbers in the glosses stand for noun classes. 
(v) Post-verbal Particle as in Ngoni P.13 (Ngonyani field notes)
a. m-geni_ a-tol-ili u-gimbi 1-guest 1SM-take-PF 14-beer 'The guest took beer.'
b. m-geni a-tol-i lepa u-gimbi 1-guest 1SM-PT-take-FV NEG 14-beer 'The guest did not take beer.'

(vi) Pre-initial Prefix + Affix as in Modern Standard Swahili G. $42^{3}$
a. tu-li-ondok-a we-PT-leave-FV 'We left.'
b. ha-tu-ku-ondok-a NEG-we-NEG+PT-leave-FV 'We did not leave'

The nature of double marking of negation as found in Swahili, Zulu (S.42), Luvale (K.14), Venda (S.21) and other languages is not discussed in this paper and is deferred to future research.

The interesting feature is that when it comes to relative clauses, languages exhibit the same patterns. For example, languages with preverbal negative particles have periphrastic negative markers in relative clauses regardless of whether they are closely related or not. The patterns of negation in relative clauses are presented in the following section.

\section{Negative Marking Strategies in Relative Clauses}

The wide range of strategies is narrowed in relative clauses as shown in this section. Using the sample languages cited in the preceding section, we notice some interesting restrictions.

In root clauses, Hung'an negation is marked by a preverbal negative particle. In relative clauses, negation is marked with a periphrastic element that is inflected for tense and subject agreement. The same applies to Mbukushu (K.43).
a. kit ki a-swiim-in Kipes zoon (Takizala 1973:128) 7chair 9REL 1SM-buy-PT Kipese yesterday 'the chair that Kipese bought yesterday'
b. kit ki a-khoon-in Kipes ku-suum
7chair 7REL 1SM-fail-past Kipese INF-buy
'the chair that Kipese didn't buy'
*kit ki lo a-swiim-in Kipes

\footnotetext{
${ }^{3}$ Standard Swahili examples are provided by the author.
} 
The negative marker appears between the relative marker and the subject of the relative clause.

Luba and languages such as Ganda (J.15), Haya (J.22), Shambala (G.23) and Nyoro-Tooro (J.11) mark negation in pre-initial morphological slot in main clauses, but use the post-initial slot in relative clauses as shown the Luba example below.
a. mú-úntú ú-twa-aká-biik-íle 1-person 1REL-we-PT-call-PF
(Yukawa 1992:341) 'the person whom we called'
b. mú-úntú ú-tu-di-ká-tu-yi-biik-íle 1-person 1REL-we-NEG-PT-we-3OM-call-PF 'the person whom we did not call'

Languages that use the post-initial slot in matrix clauses, such as Pangwa (G.64), Lozi (K.21), and Tuki (A.64), use the same strategy in the relative clauses as illustrated with Nyakyusa below.

(10) a. un-dindwana u-yo a-piy-ile mbatata (Ngonyani field notes) 1-girl 1-REL 1SM-cook-PF 10potato 'the girl who cooked potatoes'
b. un-dindwana u-yo a-ka-piy-ile mbatata 1-girl 1-REL 1SM-NEG-cook-PF 10potato 'the girl who did not cook potatoes'

The negative marker is in the post-initial slot, the same as in the matrix clauses.

It was noted that Nkoya marks negation by means of a postfinal marker in the main clause. In relative clauses, Nkoya marks negation by means of an inflected auxiliary word.
a. mu-ntu é-mon-ené
1-person 1REL-see-PT
(Yukawa 1987:161)
'a person whom he saw'
b. mu-ntu bá-bul-ilé ku-môn-a
1-person ?2SM-lack-PF INF-see-FV
'the person who they did not see'

The periphrastic negative marker is derived from kubula 'to lack'. Languages that use a post-final negation marker in matrix clauses use a periphrastic form in the relative clause.

Kingoni, Kindendeule, and Kimatuumbi mark negation the same way in the root clauses as well as in relative clauses, by means of a postverbal particle. 


a. m-geni mwe-a-tol-ili u-gimbi (Ngonyani: field notes)
1-guest 1REL-1SM-take-PF 14-beer
'the guest who took the beer.'
b. m-geni mwe-a- tol-ili $\quad \underline{\text { lepa }}$ u-gimbi
1-guest IREL-1SM-PT-take-FV NEG 14-beer
'the guest did not take beer.'

The asymmetries show that while there are six different strategies for marking negation in the main clauses, there are only three for relative clauses. In the following sections, I attempt to provide a structural account for the asymmetries.

\section{V-to-I-to-C}

The asymmetry is reminiscent of word order asymmetries found in V2 languages such as Swedish. Consider the position of negation in root clauses and relative clauses in Swedish.
a. Ulf köpte inte boken (Holmberg and Platzach 1995:45) Ulf bought not the-book
b. att Ulf inte köpte boken that Ulf not bought the-book

In the root clause (13a), the negative appears after the verb while in the subordinate clause (13b), the negative marker appears before the verb. This asymmetry is accounted for by verb movement to $C^{\circ}$ in matrix clauses, while in the subordinate clause $\mathrm{C}^{\circ}$ is filled by the complementizer. Therefore, the verb does not move to $\mathrm{C}^{\circ}$ in the subordinate clause. In languages where there is no $\mathrm{V}$ movement to $\mathrm{C}^{\circ}$ such as English, there is no asymmetry between negation in main clauses and subordinate clauses. The negation marker appears between the auxiliary and the verb in both clauses.

A good starting point for Bantu languages, therefore, is to investigate the contrast between languages that have verb movement to $\mathrm{C}^{\circ}$ and those that do not have such movement. Based on evidence from VP ellipsis and VP adverbs in Swahili and Ndendeule ${ }^{4}$, Ngonyani $(1996,2000)$ argues that the verb moves to Infl. Demuth \& Harford (1999) find evidence of verb movement to $C$ in object relative clauses of several Bantu languages. They show that Bantu languages with independent relative markers do not exhibit subject-verb inversion, while languages with an affixal relative marker do as the following contrast between Sotho (14a) and Shona (14b) shows (Demuth \& Harford 1999:42).
a.
Setula seo basadi
ba-se-rek-ile-ng
kajeno
7chair 7REL 2women 2AGR-7OBJ-buy-PERF-RL today
'the chair which the women bought today'

\footnotetext{
${ }^{4}$ Not classified by Guthrie (1967-7I) but its closest relative is Ngindo (Ngonyani 2001a).
} 


\section{b. Mbatya dza-v-aka-son-era vakadzi mw-enga 10clothes 10REL-2AGR-TN-sew-APL 2women 1bride 'clothes which the women sewed for the bride'}

The SV order is maintained in Sotho where the relative marker is an independent word, while in Shona, where the relative marker is an affix, there is subject-verb inversion. Assuming that the relative marker occupies $\mathrm{C}^{\circ}$ in Sesotho, there is no movement of the verb because the landing site is occupied. In (14b), however, the position is empty and subsequently filled by the verb.

It is tempting to hypothesize that in languages without subject-verb inversion (that is languages without verb movement to $\mathrm{C}^{\circ}$ ), there will be no asymmetry between main clauses and relative clauses because the verb does not have to cross Neg. This, however, is not borne out, as the following example from Ganda shows.
Omusajja Petero gwe a-labye mu-somesa (Walusimbi 1996:37) man Peter REL 1SM-see-PF 1-teacher
'The man that Peter has seen is a teacher.'

This example of object relativization shows two important features of Ganda relative clauses: (a) an independent word for a relative marker, and (b) no subjectobject inversion. These two facts suggest there is no verb movement to $\mathrm{C}^{\circ}$. However, negation marking is asymmetrical as the following examples show.
a. ye a-ta-kol-a
(Ashton et. al. 1954:138)
IREL ISM-NEG-work-FV
'(he) who does not work'
b. ebi-kopo te-byt-ise
8-cup NEG-crack-PF
'The cups are not cracked.'

Example (16a) shows that the negative marker in the relative clause appears after the subject marker (post-initial) different from what is found in the root verbs (16b), a pre-initial affix. Therefore, the asymmetries cannot be explained in a straightforward manner simply by appealing to V-to-I-to-C.

A closer look at the data reveals that in relative clauses, the relative marker is always associated with finiteness and more specifically TP. The relative marker, whether prosodically independent or not, is followed by a subject marker and a tense marker on the verb. Assuming an Agr-less clause structure (Chomsky 1995), we find the relative marker adjacent to the tense marker. This suggests selectional relations between the $C$ of the relative clause and TP. In languages with pre-initial negation or independent particle before the verb in main clauses, the structure cannot be embedded as a relative clause because the $\mathrm{C}$ of the relative marker will fail to govern TP. Another strategy is used instead. The selection of 
TP by $\mathrm{C}$ is very widespread among Bantu languages. Let us consider how this feature accounts for the asymmetries in the various languages.

\section{Analysis}

The correlation between the tense marker, the relative marker, and the negative marker suggests that Neg blocks government of TP by $\mathrm{C}^{\circ}$. Therefore, negation projects a NegP which selects TP. In subordinate clauses, the negative marker cannot intervene between the relative marker and the tense marker. The asymmetry between matrix clauses and relative clauses can be characterized as NegP selecting TP in matrix clauses, and NegP selected by TP in relative clauses. This is illustrated in the following abbreviated tree diagrams for Hungan sentences repeated here for verbs cited earlier.
a. $\quad \underline{\text { lo }}$ i-meen kiti
NEG I-saw 7-chair
'I didn't see the chair.'
b. kit ki a-khoon-in Kipes ku-suum
7chair 7REL 1SM-fail-past Kipese INF-buy
'the chair that Kipese didn't buy'

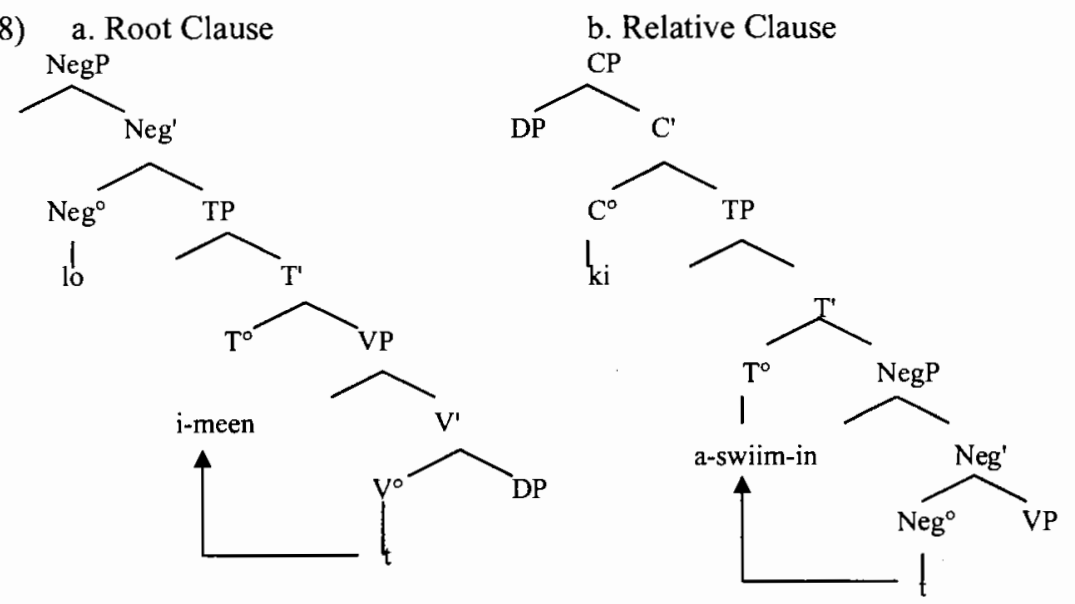

In the matrix clause, Neg appears as the highest Infl which selects TP. This accounts for the preverbal negation $l o$. The verb, which is lower than TP, raises and incorporates onto $T$ in an antisymmetric fashion (Kayne 1994). In the relative clause, however, CP does not select NegP. It selects TP, and negation has to be expressed in the form of a periphrastic marker generated as a verb and raised to $T$ in the regular V-to-I manner.

The inability of the negative marker to license TP is also found in languages with pre-initial negation such as Oruhaya and postfinal negation such as Nkoya. Let us consider Nkoya negation since it requires a periphrastic negative marker in 
relative clauses in the same way Hung'an does. In matrix clauses, negation selects TP. This negative marker attracts Tense resulting in the incorporation of the inflected verb to Neg. This explains the appearance of the negative ha in verb final position. In relative clauses, however, CP selects TP. NegP between CP and TP blocks this relation. Thus, the regular negation is eliminated and negation is introduced by a negative verb buli 'fail'. This is shown in the following pair of tree diagrams.
a. ná-mon-eně-ha
I-see-PT-NEG
'I did not see.'
b. mu-ntu bá-bul-ilé ku-môn-a 1-person ?2SM-lack-PF INF-see-FV
'the person whom they did not see'

(20)

a. Root Clause

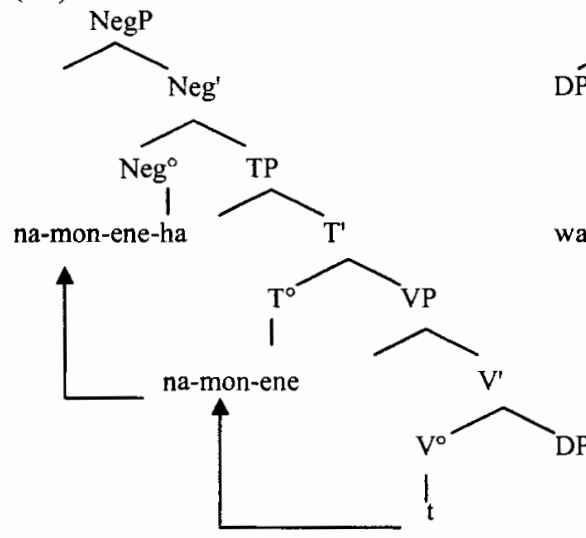

b. Relative Clause
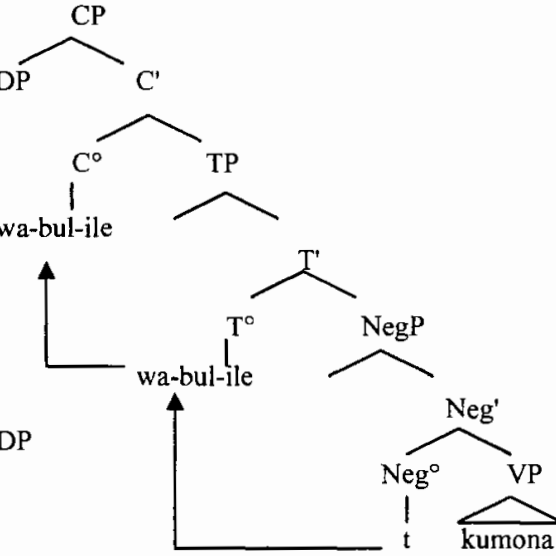

This account provides a simple explanation for the appearance of the negative suffix at the end of the verb phrase as in (20a). In such cases, the entire VP raises to Spec, NegP.
a. ná-mon-ene-há ngombe
I-see-PT-NEG 9cow
'I did not see the cow'
b. Ná-mon-ene ngombě-
I-see-PT 9cow-NEG
'I did not see the cow.' 
These two sentences show the two alternative slots for the negative affixes, namely, as a verbal suffix or as an affix on the final element of the verb phrase.

Note that the two negative markers in the matrix clauses and the relative clauses are phonologically different suggesting different origins. The different origins explain also the different affixes used in Haya where negation is a preinitial affix is different from the post-initial negation marker of the relative clause (Rubanza 1988:104-105).

(22) a. Aba-ntu ba Kanyigo ti-ba-ka-yombek-ile shule 2-people of Kanyigo NEG-2SM-RP-build-PF school

'Kanyigo people have not build the school.'
b.
A-ba-ta-a-shom-e
ti-ba-a-sing-e
mitiani
REL-2SM-NEG-IP-study-SUBJ NEG-2SM-IP-pass-SUBJ exams
'those who will not study will not pass the exams'

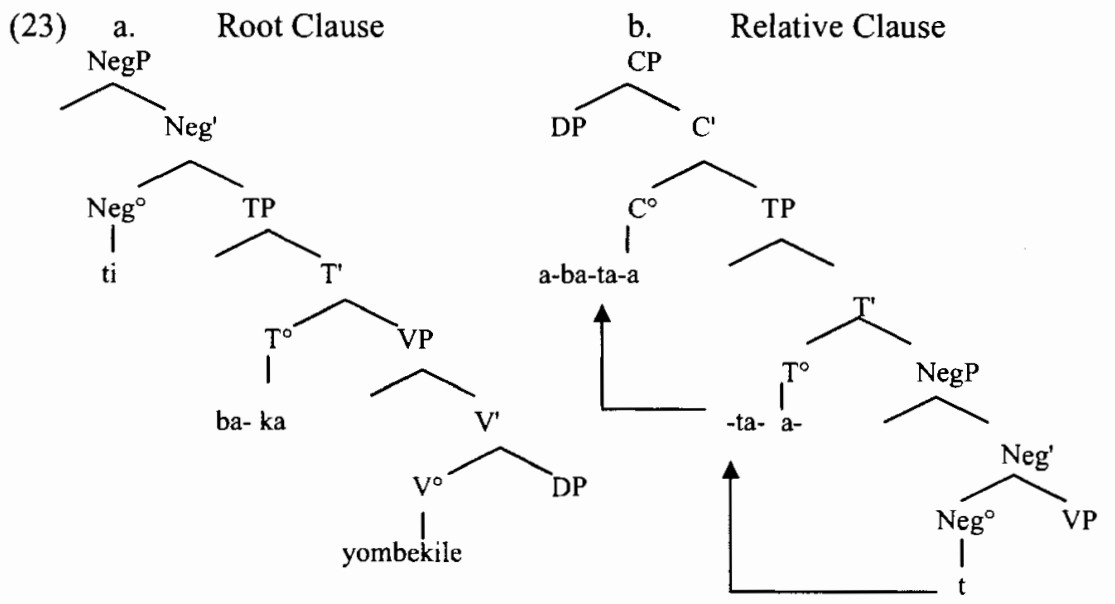

In root clauses, the negative marker appears as a clitic that is attached to the verb and is a head that selects a TP. In relative clauses, the CP selects TP, and negation is generated lower than TP. The negation marker raises and incorporates onto $\mathrm{T}^{\circ}$ and finally raises to $\mathrm{C}^{\circ}$ where the relative marker is marked under Spec-Head.

The languages in which the negation marker is in post-initial position in both root and relative clauses as in Nyakyusa, the TP selects NegP in both. Neg then incorporates onto $\mathrm{T}^{\circ}$ as the following two structures from Nyakyusa show.
a. tu-ka-a-piy-ile
we-NEG-PT-cook-PF
'We did not cook.' 

b.
un-dindwana u-yo a-ka-piy-ile
mbatata
'the girl who did not cook potatoes'

(25)

a. Root Clause
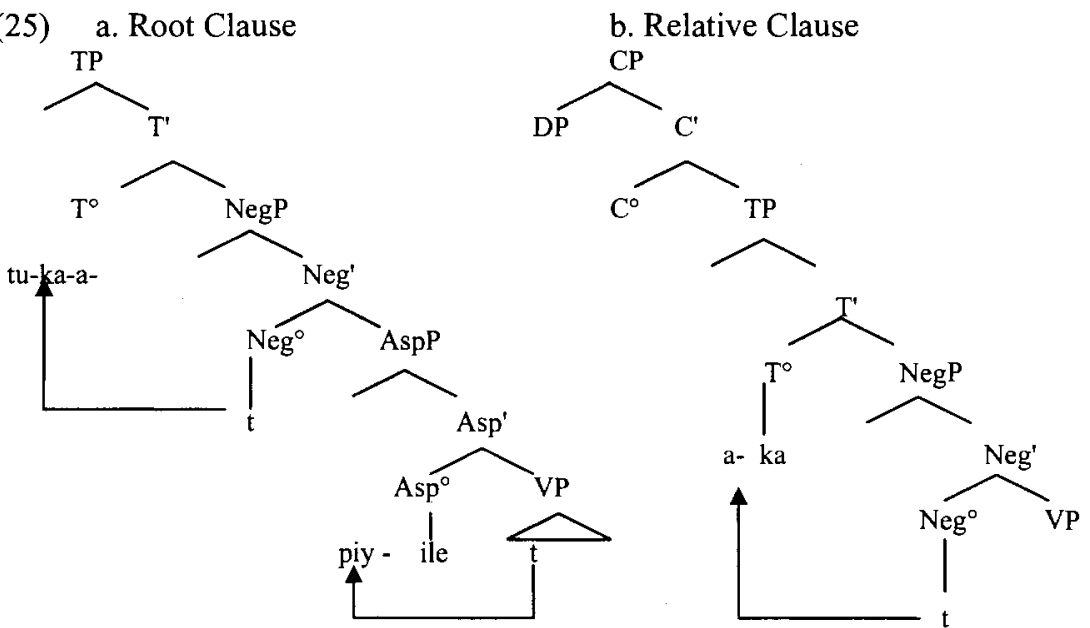

The post-verbal negative particle does not exhibit the root clause-relative clause asymmetry. Ngonyani $(200 \mathrm{lb})$ noted that the negative particle in Ndendeule does not prevent movement of the verb. Assuming Ngonyani's analysis in which the particle is generated higher than the VP in order to have scope over it, more specifically, in the Spec, NegP with an empty $\mathrm{Neg}^{\circ}$, the structure below is proposed.
a. m-geni a-tol-i lepa u-gimbi
1-guest 1SM-PT-take-FV NEG 14-beer
'The guest did not take beer.'
b. m-geni mwe-a-tol-ili lepa u-gimbi
1-guest 1REL-1SM-PT-take-FV NEG 14-beer
'The guest did not take beer.'

The verb raises to the empty $\mathrm{Neg}^{\circ}$ and subsequently to $\mathrm{T}^{\circ}$. As in other Bantu languages, the subject marker is an agreement marker, a feature assigned under Spec-Head configuration. The symmetric negation marking is due to TP selecting NegP in both root and relative clauses. 
(27)

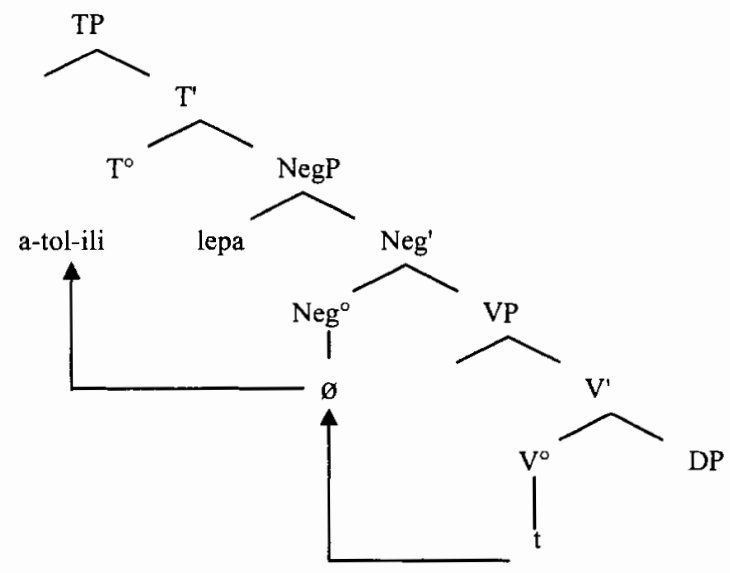

\section{Conclusion}

To conclude, in section 2, two questions were raised: (a) What is the status of Neg?, and (b) Where is Neg located in the clause structure?

For the first question, data indicate that negation projects a NegP consistent with Pollock's (1989) proposal. This is based on two considerations. One is the selectional relations between Neg and Tense which suggest in most of the languages, the negative markers are Neg. The second consideration is that the asymmetries result from avoiding the root Neg from blocking or preventing $\mathrm{C}^{\circ}$ from governing TP. As for the second question, we find two Neg positions. One NegP selects TP, and the other TP selects NegP. This supports findings in other languages such as Romance where Zanuttini (1997) has observed that several $\mathrm{NegPs}$ can be found in the clause structure.

This study made use of data from several languages which are not cited here. However, the analysis presented in 4 predicts the negation marking in them. Further research is needed to determine whether the predictions are borne out in all languages.

\section{References}

Ashton, E., E. Mulira, E. Ndawula, \& A. Tucker. 1954. A Luganda Grammar. London: Longmans, Green and Co.

Chomsky, Noam. 1995. The Minimalist Program, Cambridge, Mass.: MIT Press. Demuth, Katherine \& Carolyn Harford. 1999. Verb raising and subject inversion in Bantu relatives. Journal of African Languages and Linguistics 20(1):41-61.

Güldemann, Tom. 1999. The genesis of verbal negation in Bantu and its dependency on functional features of clause types. In Jean-Marie Hombert \& Hyman, Larry (eds.) Bantu Historical Linguistics. Stanford: CSLI. 
Guthrie, Malcolm. 1967-71. Comparative Bantu. Vols. 1-4. Farnborough: Gregg Press.

Holmberg, Anders \& Christer Platzach. 1995. The Role of Inflection in Scandinavian Syntax. New York: Oxford University Press.

Kayne, Richard. 1994: The Antisymmetry of Syntax, Cambridge, MA: MIT Press. Meeussen, Achilles E. 1967. Bantu grammatical reconstructions. Africana Linguistica III: 79-121.

Ngonyani, Deo. 2001a. The evolution of Tanzanian Ngoni. Sprache und Geschichte in Afrika 16/17: 321-353.

Ngonyani, Deo. 2001b. The relevance of tense for sentential negation in Kindendeule. Paper presented at the $32^{\text {nd }}$ Annual Conference on African Linguistics, University of California, Berkeley.

Ngonyani, Deo. 2000. VP ellipsis in Kindendeule. In Kulikoyela Kahigi, Yared Kihore, \& Maarten Mous (eds.) Languages of Tanzania, 215-232. Leiden University: Research School CNWS.

Ngonyani, Deo. 1996. The Morphosyntax of Applicatives. PhD dissertation, University of California Los Angeles.

Pollock, Jean-Yves. 1989. Verb movement, universal grammar and the structure of IP. Linguistic Inquiry 20: 365-424.

Rubanza, Yunus, I. 1988. Linear Order in Haya Verbal Morphology: Theoretical Implications. PhD dissertation, Michigan State University.

Rubongoya, L. T. 1999. A Modern Rutoro-Runyooro Grammar. Köln: Rudiger Köppe.

Takizala, Alexis. 1973. Focus and relativization. In John Kimball (ed.) Syntax and Semantics Vol. 2., 123-149. New York: Seminar Press.

Walusimbi, Livingston. 1996. Relative Clauses in Luganda. Köln: Rüdiger Köppe Verlag.

Yukawa, Yasutoshi. 1987. A tonological study of Nkoya verbs. In Studies in Zambian Languages, 129-184. Tokyo: Institute for the Study of Languages and Cultures of Asia and Africa.

Yukawa, Yasutoshi. 1992. A Tonological study of Luba verbs. In Studies in Cameroonian and Zairean Languages. Tokyo: Institute for the Study of Languages and Cultures of Asia and Africa.

Zanuttini, Raffaella. 1997. Negation and verb movement. In Liliane Haegeman (ed.) The New Comparative Syntax, 214-245. London: Longman.

Department of Linguistics and Germanic, Slavic, Asian and African Languages A-614 Wells Hall Michigan State University

East Lansing, MI 48824

ngonyani@msu.edu 